\title{
Abordagem da variação terminológica em uma base de dados de combinatórias léxicas
}

\section{Approaching terminological variation in a data base of lexical combinations}

\author{
Anna Maria Becker Maciel \\ Patrícia Chittoni Ramos Reuillard*
}

Resumo: O objetivo deste texto é mostrar como o fenômeno da variação linguística é abordado em uma base de dados on-line orientada para o tradutor, contendo combinatórias léxicas da linguagem legal em português, com equivalentes em alemão, espanhol, francês, inglês e italiano. Entendemos a variação terminológica como a utilização de formas lexicais diferentes para referir o mesmo conceito ou expressar a mesma função no contexto discursivo da comunicação especializada. A variação abrange mudanças morfológicas e sintáticas, inserção de itens e ocorrência de sinonímia. Primeiro, delineamos nosso quadro referencial teórico; depois de descrever e categorizar as combinatórias variantes, coletadas em um corpus comparável multilíngue da legislação ambiental, comentamos sua disposição na microestrutura da base.

Palavras-chave: Variação terminológica; Base de dados Terminológica; Tradução; Linguagem legal; Terminologia ambiental.

Abstract: The aim of this text is to show how the linguistic phenomenon of variation is approached in a translator-oriented data base online storing lexical combinations

* Professoras da Universidade Federal do Rio Grande do Sul, Programa de Pós-Graduação em Letras; anna.maciel@ufrgs.br e patrícia.ramos@ufrgs.br. 
MACIEL, A. M. B.; ReUILLARD, P. C. R. - Abordagem da variação terminológica em uma base de dados de combinatórias léxicas

of legal language in Portuguese with equivalent expressions in German, Spanish, French, English and Italian. We understand terminological variation as the use of various lexical forms referring to the same concept or meaning with the same function within the discursive context of specialized communication. Lexical combination variation encompasses morphological and syntactic changes, insertion of items and occurrence of synonymy. First, we out line our theoretical reference frame; then, we describe and categorize the variant combinations collected in a multilingual comparable corpus of environmental legislation and their presentation on the database microstructure.

Keywords: Terminological variation; Terminological Data Base; Translation; Legal Language; Environmental Terminology.

\section{Introdução}

No processo de construção de uma base de dados on-line de combinatórias léxicas especializadas (CLEs) em português, com equivalências para alemão, espanhol, francês, inglês e italiano, o tratamento dado à variação terminológica e sua apresentação é o foco deste trabalho. Os principais aspectos levados em conta são, de um lado, a descrição do fenômeno linguístico, tendo em vista atender às necessidades do tradutor e, de outro, seu acesso às informações disponibilizadas no verbete.

A variação terminológica é aqui entendida como a utilização de formas lexicais diferentes para referir o mesmo conceito ou expressar a mesma função no contexto discursivo da comunicação especializada. Nessa ampla perspectiva, a variação terminológica de combinatórias léxicas abrange não somente mudanças morfológicas e sintáticas, mas também inserção de itens e ocorrência de sinonímia.

Segundo Daille (2007: 163), a presença da variação terminológica nos textos especializados é estimada atualmente em uma proporção de $15 \%$ a 35\%, 
MACIEL, A. M. B.; ReUILLARD, P. C. R. - Abordagem da variação terminológica em uma base de dados de combinatórias léxicas

dependendo do gênero textual e da área. Tal frequência atrai cada vez mais o interesse de pesquisadores em línguas e domínios diversos. Além de Daille, destacamos no estudo do tema, entre outros linguistas, Habert, Jacquemin, Royauté (2000), Faulstich (2001) e Freixa (2002; 2013) no inglês, no português e no espanhol respectivamente. Via de regra, as pesquisas concentram-se nas unidades terminológicas (UT) propriamente ditas, deixando de lado as unidades de significação especializada (USE), que são também elementos relevantes na configuração da linguagem das áreas temáticas. Assim sendo, o tema da variação das combinatórias léxicas em textos especializados ainda mostra-se esparso na revisão bibliográfica da área. Além disso, são raras as obras dicionarísticas direcionadas ao tradutor e ao redator de documentos oficiais que apresentam combinatórias léxicas da linguagem legal.

Neste texto, apresentamos, em primeiro lugar, as grandes linhas do quadro referencial teórico em que se insere a nossa visão de variação de combinatórias; em seguida, descrevemos e categorizamos as combinatórias variantes coletadas no nosso corpus de estudo. Finalmente, comentamos as soluções adotadas na organização da microestrutura do verbete.

\section{Quadro referencial}

\subsection{Variação e combinatórias}

A variação como "conjunto das diferenças de realização linguística (falada ou escrita) pelos falantes de uma mesma língua, decorrentes do fato de o sistema linguístico não ser unitário, pois comporta diversos eixos de diferenciação: estilístico, regional, sociocultural, ocupacional e etário [...]" (HouAlss 2001), tem sido abordada de diversas formas. Adotamos aqui a visão 
MACIEL, A. M. B.; ReUILLARD, P. C. R. - Abordagem da variação terminológica em uma base de dados de combinatórias léxicas

da Teoria Comunicativa da Terminologia - TCT - e da Linguística de Corpus LC -, cujos pressupostos subjazem à nossa pesquisa e enfatizam que a variação linguística é um fenômeno normal e esperado.

Buscamos apoio em pesquisadores contemporâneos cujos trabalhos terminográficos refletem os mesmos princípios que priorizamos. Assim, em sintonia com L'Homme (2004: 72-74) consideramos como variação terminológica as mudanças que as combinatórias léxicas especializadas sofrem no contexto da comunicação. Também acreditamos que o seu tratamento terminográfico deve ser diferente daquele preconizado para obras lexicográficas gerais, embora essa variação seja semelhante àquela que ocorre na língua comum (L'Homme, BerTRANd 2000). Buscamos Heid e Freibott (1991), pioneiros na apresentação de combinatórias em uma base de dados dirigida ao tradutor especializado, e ainda consultamos as recomendações de Gouadec (1994) a respeito do seu tratamento terminográfico.

A TCT exige que, tanto do ponto de vista teórico como do metodológico, se contemple a variação linguística em toda sua dimensão (CABRÉ, 1999). Quanto à LC, destacamos que as pesquisas de Biber et al, (1998) e Sinclair (1991) demonstram que a língua em uso se caracteriza por apresentar regularidades de padrões com uma variação sem fim, de tal modo que os falantes têm à sua escolha uma seleção de combinações mais ou menos fixas de palavras coocorrentes.

A formação de combinatórias é um processo inconsciente e natural que se desenvolve gradativamente quer na língua geral, quer na linguagem especializada e se consolida pelo uso repetido em contextos determinados. A coesão que se verifica entre seus itens constitutivos não pode ser explicada pela sintaxe ou pela semântica, mas apenas pelo consenso de sua aceitação entre os falantes de uma dada área de conhecimento ou atividade. 
MACIEL, A. M. B.; ReUILLARD, P. C. R. - Abordagem da variação terminológica em uma base de dados de combinatórias léxicas

\subsection{Variação e combinatórias na linguagem legal}

A linguagem utilizada no texto legislativo apresenta combinações que se repetem, configurando padrões linguísticos que, embora constituídos por itens lexicais da língua comum, são prototípicos do universo jurídico. Tais padrões configuram o que denominamos Combinatórias Léxicas Especializadas da Linguagem Legal - CLEs, por exemplo, "no uso das atribuições que the confere a lei", "para os efeitos desta lei", "revogam-se as disposições em contrário" e "entra em vigor na data desta publicação". São combinações de palavras que coocorrem mais frequentemente do que se poderia esperar se sua justaposição fosse resultado do mero acaso.

Os manuais de redação legislativa de línguas e sistemas jurídicos diversos desaprovam a variação lexical no texto da lei por considerarem sua utilização um obstáculo à clareza, à precisão e à univocidade. Não obstante, combinatórias variantes foram encontradas no nosso corpus da pesquisa, constituído por recortes da legislação ambiental do Brasil, Alemanha, Argentina, Canadá, Estados Unidos, Itália, França, Paraguai e Uruguai. Por exemplo, a variação de "de acordo com a lei" foi observada no uso das combinatórias "de acordo com as disposições da lei", "de acordo com o que dispuser a lei", "de acordo com o previsto na lei", além das formas sinonímicas "conforme a lei", "nos termos da lei", "na forma da lei" e "em concordância com a lei". O exame do seu contexto demonstrou que todas essas formas variantes desempenham a mesma função sintática, semântica e pragmática no texto legislativo.

Tal fenômeno linguístico constitui um problema para a redação e para a busca de equivalências tradutórias de textos da lei. Qual é o equivalente da combinatória acima comentada? Em inglês, será "according to [legislative text]" ou "pursuant to [legislative text]"? E, em francês, "conformément à [texte législatif]" ou "selon les formes prévues par [texte législatif]", ou 
MACIEL, A. M. B.; ReUILLARD, P. C. R. - Abordagem da variação terminológica em uma base de dados de combinatórias léxicas

ainda "selon les dispositions de [texte législatif]"? Assim, parece não haver razão para dizer "anulam-se" ou "cancelam-se as disposições em contrário", ao invés de "revogam-se"? Ou porque não se pode substituir "efeitos" por "propósitos" ou "finalidades" na expressão "para os efeitos desta lei"?

Algo semelhante ocorre também quando se trata de combinatórias características da área temática regulamentada por legislação específica, como, em nosso corpus, a área ambiental. Diante da combinatória "beneficiamento de resíduos de construção", o que escolher para a língua francesa: "traitement des déchets de chantier" ou "traitement de déchets de bâtiment"? Sem falar em outros exemplos encontrados em nossa base de dados que apresentam a mesma problemática; por exemplo, para a combinatória "adução de água", qual o melhor equivalente em inglês: "water adduction" ou "water conveyance"? No caso de "transporte de resíduos", qual o equivalente mais adequado em alemão: "Beförderung von Abfällen" ou "Abfallbefördern "?

\section{CLEs da Legislação ambiental}

As combinatórias léxicas da linguagem jurídico-ambiental que compõem a nossa base de dados dividem-se em dois grandes grupos: as CLEs discursivas e as CLEs terminológicas. As primeiras desdobram-se em CLEs legais, utilizadas em documentos de qualquer ramo do Direito, como Direito constitucional, jurisprudencial, civil, comercial, penal, entre outros, como "para os fins deste decreto", e em CLEs legislativas, utilizadas exclusivamente em textos legislativos, tais como "Esta lei entra em vigor na data de sua publicação". As CLEs terminológicas, por sua vez, são prototípicas do domínio temático da legislação ambiental, por exemplo, "avaliação da qualidade ambiental". Ambos os grupos têm caráter deôntico, isto é, exprimem o valor 
MACIEL, A. M. B.; ReUILLARD, P. C. R. - Abordagem da variação terminológica em uma base de dados de combinatórias léxicas

modal de obrigação inerente ao universo discursivo da lei. Tanto um grupo como o outro contém ao menos um núcleo especializado: as CLEs discursivas contêm termos de Direito, enquanto as CLEs terminológicas contêm termos do Direito do meio ambiente (BEVILACQUA 1996, BeVILACQUA et al. 2013).

\subsection{CLEs legais}

No texto legislativo, as CLES legais localizam-se,em geral, na microestrutura de um artigo, no início ou no final de uma oração ou intercaladas dentro de uma CLE legislativa. Expressam funções pragmáticas próprias do sistema jurídico, tais como a autorregulamentação da lei ("conforme o artigo 22 do Decreto..."), o acarretamento legal ("para os efeitos desta Lei") e a fundamentação da competência do emissor ("no uso das atribuições que the confere o artigo 84"). Na perspectiva morfossintática, projetam a estrutura matricial de uma base fixa e de um coocorrente variável: BASE+COLOCADO.

A parte fixa - BASE - é uma unidade lexical da língua comum, mono ou multivocabular, que se combina com um COLOCADO, unidade léxica temática variável própria da linguagem especializada do Direito, isto é, um termo jurídico. Por exemplo: a base "de acordo com" combina-se com o termo que se refere a um texto legislativo ou com parte dele, formando a CLE "de acordo com a Constituição", ou "de acordo com o disposto no Artigo 14, da Lei $\mathrm{n}^{\circ}$ 6.938/81".

As CLEs legais assumem preferencialmente três estruturas morfossintáticas: locução adverbial iniciada por preposição, funcionando como adjunto circunstancial ("conforme o artigo 22 da lei"); orações reduzidas de gerúndio ("Considerando [texto legislativo ou parte de texto legislativo]"); orações reduzidas de particípio passado ("observado o disposto no caput desta Lei"). 
MACIEL, A. M. B.; ReUILLARD, P. C. R. - Abordagem da variação terminológica em uma base de dados de combinatórias léxicas

Nos exemplos seguintes, observa-se a variação da CLE "de acordo com [texto legislativo ou parte de texto legislativo]" utilizada no exemplo (1), que em (2) aparece com a intercalação da expressão "disposições deste Código"; por sua vez em (3) ocorre uma substituição sinonímica da preposição inicial "conforme" ao invés de "de acordo com".

(1) “O lote familiar, cuja dimensão deverá corresponder à área mínima de produção capaz de assegurar a promoção econômica e social do irrigante e sua família, constitui propriedade resolúvel e indivisível, de acordo com esta Lei."

(2) "Os Estados exercerão, dentro dos respectivos territórios, as atribuições que thes forem conferidas, de acordo com as disposições deste Código e com relação a todas as fontes de energia hidráulica."

(3) "Respeitados o prazo previsto no ato declaratório e suas eventuais prorrogações, conforme o parágrafo anterior, compete ao CNTur aprovar os planos e programas ali referidos."

O exemplo (4) abaixo ilustra a CLE "Considerando [texto legislativo ou parte de texto legislativo]", que configura um adjunto adverbial, frequentemente intercalado na fórmula da promulgação, na parte introdutória de Decretos, Resoluções e Portarias. Sua função é enumerar causas, motivos, argumentos, razões que justificam a criação da norma. 0 exemplo (5) apresenta a mesma CLE com a inserção de "o que prevê".

(4) "Considerando os artigos 104 e 131, entre outros dispositivos, da Lei 9.503 de 23 de setembro de 1997, que institui o Código de Trânsito Brasileiro - CTB; RESOLVE: [...]". 
MACIEL, A. M. B.; ReUILLARD, P. C. R. - Abordagem da variação terminológica em uma base de dados de combinatórias léxicas

(5) "Considerando o que prevê o artigo $4^{\circ}$ da Lei $n^{\circ} 7.661$, de 16 de maio de 1988, que institui o Plano Nacional de Gerenciamento Costeiro, DECRETA".

O exemplo (6) mostra a variação da CLE "Observado [texto legislativo ou parte de texto legislativo]", utilizada como oração reduzida de particípio passado, estabelecendo uma condição concessiva. Já em (7) aparecem mudanças gramaticais devido à intercalação de um novo item lexical, "as disposições" e, no exemplo (8), coocorre a variante sinonímica "respeitado" ao invés de "observado".

(6) "Nas águas de domínio privado, é necessário para pescar o consentimento expresso ou tácito dos proprietários, observados os arts. 599, 600, 601 e 602 do Código Civil."

(7) "Os Estados estabelecerão, por decreto, as normas a que deverão submeter-se os projetos de loteamento e desmembramento nas áreas previstas no Artigo 13, observadas as disposições desta Lei."

(8) "O plano municipal de gestão integrada de resíduos sólidos pode estar inserido no plano de saneamento básico previsto no art. 19 da Lei no 11.445, de 2007, respeitado o conteúdo mínimo previsto nos incisos do caput $e$ observado o disposto no $\S 20$, todos deste artigo."

\subsection{CLEs legislativas}

As CLEs legislativas configuram fraseologias ritualizadas da linguagem legislativa que, de acordo com Kurzon (1986) e Maciel (2001), realizam atos de fala jurídicos. Sua localização na macroestrutura do texto é estabelecida pelas rubricas de redação e editoração oficiais de cada país e de cada sistema 
MACIEL, A. M. B.; ReUILLARD, P. C. R. - Abordagem da variação terminológica em uma base de dados de combinatórias léxicas

jurídico. Trata-se de atos prototípicos do Direito Constitucional, tais como a promulgação, a revogação, a vigência de uma norma legal e a atribuição de poder. São estruturas formulaicas próprias de determinadas ações jurídicas. Seu enunciado semifixo não admite padronização, mas pode sofrer variações morfológicas de acordo com restrições circunstanciais do contexto extralinguístico.

Nos exemplos (9) e (10) a seguir, observa-se que a fórmula da promulgação apresenta a mudança de gênero correspondente à pessoa que, no momento, ocupa a presidência da República, enquanto no exemplo (11) a variação é motivada pela posição hierárquica de quem promulga a lei. Em ambos os casos, a CLE legislativa que enuncia o ato de fala é semântica e pragmaticamente a mesma, ainda que sua expressão lexical seja diferente.

(9) "O PRESIDENTE DA REPÚBLICA Faço saber que o Congresso Nacional decreta e eu sanciono a seguinte Lei: [...]".

(10) "A PRESIDENTA DA REPÚBLICA Faço saber que o Congresso Nacional decreta e eu sanciono a seguinte Lei: [...]".

(11) "Faço saber que o Presidente da República adotou a Medida Provisória $n^{\circ}$ 34, de 1989, que o Congresso Nacional aprovou, e eu, Nelson Carneiro, Presidente do Senado Federal, para os efeitos do disposto no parágrafo único do art. 62 da Constituição Federal, promulgo a seguinte Lei: [...]”.

Os exemplos (12) e (13) abaixo ilustram uma variação sintática de tempo verbal que não acarreta mudança semântica ou pragmática e que pode ser usada aleatoriamente uma vez que, em ambos os casos, está implícita a ideia de futuro em tempos verbais gramaticais diferentes. 
MACIEL, A. M. B.; ReUILLARD, P. C. R. - Abordagem da variação terminológica em uma base de dados de combinatórias léxicas

(12) "Esta Lei entra em vigor na data de sua publicação."

(13) "Esta Lei entrará em vigor na data de sua publicação."

Cumpre observar que nossa seleção de combinatórias não é exaustiva. Além do padrão acima descrito, outras CLEs são também utilizadas na área jurídica, conforme apontado por Bevilacqua (1996). Ademais, também são frequentes expressões da língua comum que, embora não contenham termos jurídicos, revelam prima facies a especificidade da área, como, por exemplo, o emprego da locução "no que couber", circunscrevendo a abrangência da norma, ou o uso repetido de "considerando" na enumeração de motivos para justificar a criação de uma entidade ou de regulamentações, e ainda "dá outras providências", frase fixa que ocorre na ementa da lei. Em consonância com Gouadec (1994: 167-193), consideramos que essas fraseologias devem ser catalogadas como CLEs, uma vez que seu uso é característico do texto jurídico.

\subsection{CLEs terminológicas}

As CLEs terminológicas expressam desde ações amplas, como "conservação dos recursos marinhos vivos", até processos específicos, como "armazenamento de agrotóxicos e afins", que abrangem questões da área ambiental sobre as quais incide a legislação. Tais CLEs não são prototípicas da área jurídica, pois ocorrem também em outros domínios que se ocupam do meio ambiente; no entanto, agrupam-se em estruturas consagradas pelo uso, configurando paradigmas que não são aleatórios.

De acordo com a proposta de Bevilacqua (2004: 62-63), as CLEs terminológicas são unidades sintagmáticas de um ou mais termos formadas por um núcleo terminológico (NT) e um núcleo eventivo (NE). O NT é um termo nominal com valor referencial e denominativo. O NE é expresso por um 
MACIEL, A. M. B.; ReUILLARD, P. C. R. - Abordagem da variação terminológica em uma base de dados de combinatórias léxicas

verbo, sua nominalização ou particípio, denota atividades e processos próprios de determinada área especializada, pode ter ou não caráter terminológico. Entre os dois núcleos se estabelece uma relação sintático-semântica, uma vez que o NT é o argumento que completa o NE. Por exemplo, "acondicionamento" (NE) + "resíduos nucleares" (NT) formam a CLE “acondicionamento de resíduos nucleares". As características pragmáticas do texto conferem a ambos os núcleos e consequentemente à CLE como uma unidade sintagmática um valor especializado.

Assim como as CLEs legais e as legislativas, as CLEs terminológicas também admitem variação. A seguir, apresentamos exemplos coletados no nosso corpus.

As CLEs "abastecimento de água" no exemplo (14) e "fornecimento de água" (15) são sinônimas.

(14) "Constitui obrigação do proprietário do imóvel a execução de instalações domiciliares adequadas de abastecimento de água potável e de remoção de esgotos, cabendo ao ocupante do imóvel zelar pela necessária conservação."

(15) “[...] assegurar às populações das áreas metropolitanas, e dos outros centros urbanos, a infraestrutura mínima de fornecimento de água, de boa qualidade, de um sistema de esgotos adequado e de áreas de recreação [...]."

No exemplo (16) seguinte se observa o uso da CLE e de sua sigla, enquanto em (17) éutilizada somente a sigla.

(16) "Esta Lei estabelece normas de segurança e mecanismos de fiscalização sobre a construção, o cultivo, a produção, a manipulação, o transporte, a transferência, a importação, a exportação, o armazenamento, a pesquisa, a comercialização, o consumo, a liberação no meio ambiente e o descarte de organismos geneticamente modificados - OGM e seus derivados". 
MACIEL, A. M. B.; ReUILLARD, P. C. R. - Abordagem da variação terminológica em uma base de dados de combinatórias léxicas

(17) "Caberá aos órgãos e entidades de registro e fiscalização [...] III - emitir autorização para a importação de OGM e seus derivados para uso comercial."

\section{Tipologia da variação dasCLEs}

A variação identificada no corpus configura-se de duas formas básicas, que ilustramos a seguir.

\subsection{Variação semântica:}

i. unidades lexicais sinonímicas: "de acordo com o artigo 22" ; "conforme o artigo 22" ; "abastecimento de água"; "fornecimento de água".

ii. unidades lexicais quase sinonímicas: "considerando [texto legislativo ou parte de texto legislativo]; "tendo em vista [texto legislativo ou parte de texto legislativo]".

\subsection{Variação morfológica:}

i. alternância da forma verbal e deverbal: "armazenar produtos perigosos" e "armazenamento de produtos perigosos";

ii. alternância do modo verbal: "de acordo com o que dispõe a lei" e "de acordo com o que dispuser a lei";

iii. alternância da forma gramatical (singular/plural; masculino/feminino; voz ativa/passiva; tempo verbal): 
MACIEL, A. M. B.; ReUILLARD, P. C. R. - Abordagem da variação terminológica em uma base de dados de combinatórias léxicas

"revogadas as disposições em contrário" e "revogam-se as disposições em contrário";

iv. inserção de um elemento léxico na combinatória: "de acordo com a lei" e "de acordo como disposto nesta lei";

v. encaixe de outra CLE na combinatória: "O PRESIDENTE DA REPÚBLICA, no uso das atribuições que the confere o [texto legislativo ou parte de texto legislativo] DECRETA:[...]." e "O PRESIDENTE DA REPÚBLICA, usando das prerrogativas que the confere $O \leqslant 2^{\circ}$ do art. $9^{\circ}$ do Ato Institucional $n^{\circ} 4$, de 7 de dezembro de 1966, DECRETA:[...]";

vi. siglagem: "descarte de organismos geneticamente modificados" e "importação de OGM".

Coletadas e examinadas em contextos diferentes, as CLEs variantes não parecem revelar diferenças semânticas em seu significado, tampouco apresentam discrepância em sua função pragmática. A variação morfológica decorre por razões de concordância gramatical de gênero e número, ou por restrições sintáticas determinadas por certas formas verbais. A intercalação de elementos léxicos (os quais por sua vez configuram outras CLEs: "conforme o que prevê...", "o que dispõe...", "conforme o disposto...,") parece indicar um recurso estilístico próprio da linguagem legal. 0 uso de sinônimos é muito limitado e não foi encontrada sinonímia coocorrente em um mesmo documento.

Mais complexo que o fenômeno da variação morfossintática ou estilística é a sinonímia nos casos em que a lei usa as conjunções "e", "ou", deixando o leitor na dúvida entre uma alternância de termos com o mesmo conceito ou uma adição de dois termos e conceitos diferentes. Um exemplo problemático é a proibição do Conselho Nacional de Biossegurança de "destruição ou descarte no meio ambiente de OGM e seus derivados". Outro exemplo é "reutilizar e reciclar resíduos", onde a abrangência semântica dos 
MACIEL, A. M. B.; ReUILLARD, P. C. R. - Abordagem da variação terminológica em uma base de dados de combinatórias léxicas

dois processos mereceu pesquisa detalhada. Essa estrutura ambígua parece ser tradicional do discurso jurídico em todas as línguas e sistemas (MELLINKOFF 1994: 147-152); por segurança, preferimos considerar que, em tais ocorrências, não há sinonímia.

\section{Inserção das CLEs variantes na base de dados}

Nossa base dispõe de dois campos para a inserção de variantes. 0 primeiro, denominado OUTRAS FORMAS, é reservado para as CLEs que apresentam alguma variação morfológica em relação à CLE original: CLEs elencadas em 3.2. No campo denominado VER TAMBÉM, são inseridas as CLES sinonímicas conforme explicitado em 3.1.

Alguns equivalentes em língua estrangeira das CLEs em português também apresentam variação, mas sua descrição foge aos limites deste artigo. Conforme o que até agora foi observado, a variação se configura de modo semelhante nas línguas latinas e, com algumas pequenas diferenças, também no inglês e no alemão. Sua inserção na base é feita da mesma maneira que a das formas variantes em português, isto é, distinguindo expressões sinonímicas, colocadas no campo VER TAMBÉM, das variações morfossintáticas, no campo OUTRAS FORMAS.

\section{Considerações finais}

Buscamos descrever neste artigo o fenômeno linguístico da variação presente em combinatórias léxicas especializadas da linguagem do Direito 
MACiel, A. M. B.; ReUILLARD, P. C. R. - Abordagem da variação terminológica em uma base de dados de combinatórias léxicas

ambiental. Em que pesem as recomendações dos manuais de legística, tanto nacionais quanto internacionais, encontramos em nosso corpus, composto por extratos de legislações de países representativos de nossas línguas de trabalho (português, alemão, espanhol, francês, inglês e italiano), uma presença bastante significativa de formas variantes.

Nas análises feitas até o momento, verificamos, no entanto, que a maior incidência de variação em nosso corpus tange à variação morfológica alternância da forma verbal e deverbal, do modo verbal e da forma gramatical, inserção de elementos léxicos na combinatória ou mesmo encaixe de outra combinatória, e siglagem.

A variação semântica, visível nos sinônimos e quase sinônimos, mostrase menos produtiva, o que poderia indicar um maior respeito do legislador às recomendações de elaboração do texto legal. Todavia, identificamos alguns casos de estruturas construídas com uma sequência de palavras cujos campos semânticos parecem sobrepostos, que podem acarretar problemas de compreensão do alcance da lei, como, por exemplo, "fraudar, falsificar e adulterar agrotóxicos, seus componentes e afins", ou "carregamento, estiva e descarregamento de produtos perigosos".

Por entender que o tradutor e o redator técnico de textos especializados - nossos usuários preferenciais - devem não apenas conhecer as formas padrão das fraseologias presentes na legislação, mas também suas possíveis variantes, optamos por incluir em nossa base dedados todas as variantes encontradas, determinando para cada tipo um campo específico, independentemente da frequência. Pensamos que disponibilizando sugestões para a seleção da forma equivalente adequada ao contexto, poderíamos sensibilizar esses profissionais para o fenômeno da variação.

Esperamos ter alcançado nosso propósito de apresentar a variação terminológica, assim como o tratamento e os critérios de sua inserção na base de dados. 
MACIEL, A. M. B.; ReUILLARD, P. C. R. - Abordagem da variação terminológica em uma base de dados de combinatórias léxicas

\section{Referências bibliográficas}

BIBER, D.; et al. Corpus Linguistics. Investigating Language Structure and Use.Cambridge: Cambridge University Press, 1998.

BeVILACQUA, C. R. A fraseologia jurídico-ambiental. 1996. Dissertação [Mestrado em Letras] - Programa de Pós-Graduação em Letras, Universidade Federal do Rio Grande do Sul, Porto Alegre, 1996.

. Unidades fraseológicas especializadas eventivas: descripción y reglas de formación enelámbito de laenergía solar. 2004. Tese [Doutorado em Linguística Aplicada] - Instituto Universitário de Linguística Aplicada, Universidade Pompeu Fabra, Barcelona, 2004.

Bevilacqua, C. R.; Maciel, A. M. B.; ReUillard, P.; Scheeren, C. M.; Killian, C. K. Combinatórias Léxicas da Linguagem Legislativa: uma abordagem orientada pelo corpus. In: MURAKAVA, C. A. A.; NADIN, O. L. (Orgs.) Terminologia: uma ciência interdisciplinar. São Paulo: Cultura Acadêmica, 2013: 227-244. (Série Trilhas Linguísticas, $\mathrm{n}^{\circ}$ 22)

CABRÉ, M. T. La terminología, representación y comunicación: elementos para una teoría de base comunicativa y otros artículos. Barcelona: Universitat Pompeu Fabra, IULA, 1999.

DaIlle, B.; HABerT, B.; JaCQUemin, C.; Royauté, J. Empirical observation of term variation and principles for their description. 2000. Disponivel em: http://perso.limsi.fr/jacquemi/FTP/dailleetal-termin96.pdf. Acesso em: 14 set. 2014.

DAILLE, B. Variations and application-oriented terminology engineering. In: IbekWe-Sanjuan, F.; Condamines, A.; Cabré-CASTellví, M. T. Application-driven terminology engineering. Amsterdam: John Benjamins, 2007: 163-177. (Benjamins Current Topics, 2).

FAULSTICH, E. Aspectos de terminologia geral e terminologia variacionista. TRADTERM , n. 7, pp. 11-40, 2001.

FREIXA, J. La variació terminològica: anàlisi de lavariació denominativa en textos de diferent grau d'especialització de l'àrea de mediambient. Tesis doctoral. Barcelona: Institut Universitari de Lingüística Aplicada, Universitat Pompeu Fabra, 2002. (SèrieTesis, 3). 
MACiel, A. M. B.; ReUILLARD, P. C. R. - Abordagem da variação terminológica em uma base de dados de combinatórias léxicas

—. Otra vez sobre las causas de lavariación denominativa. Debate Terminológico, $\quad$ n. $09, \quad 2013 . \quad$ Disponível em: http://seer.ufrgs.br/riterm/article/view/37170. Acesso em: 4 maio 2014.

GOUADEC, D. Nature et traitement des unités phraséologiques. In: Terminologie et phraséologie. Paris: La Maison du Dictionnaire, 1994: 167193.

Heid, U.; Freibott, G. Collocations dansune base de données terminologiques et lexicales. META, v. 36, n.1, pp. 77-91, 1991.

HoualsS, A.; VILlaR, M.S.Dicionário Houaiss da Língua Portuguesa. Rio de Janeiro: Editora Objetiva, 2001.

KURzon, D. It is here by performed... Legal Speech Acts. Amsterdam: Benjamins, 1986.

L'Homme, M. C. Understanding Specialized Lexical Combinations. Terminology, vol. 6, n. 1, pp. 89-110, 2000.

. La terminologie: principles et techniques. Montréal: Les Presses de l'Université de Montréal, 2004.

L'Homme, M. C.; Bertrand, C. Specialized Lexical Combinations: Should they be described as collocations? Proceedings. Ninth Euralex International Congress. Stuttggart: Université de Stuttgart, 2000: 497- 506.

MACIEL, A. M. B. Para o reconhecimento da especificidade do termo jurídico. Tese [Doutorado em Letras] - Programa de Pós-Graduação em Letras, Universidade Federal do Rio Grande do Sul, Porto Alegre, 2001.

MELLINKOFF, D. The language of the law. Boston: Little, Brown, 1963.

SINCLAIR, J. Corpus, Concordance Collocation. Oxford: Oxford University Press, 1991. 